\title{
JIMMBA
}

Jurnal Ilmiah Mahasiswa Manajemen, Bisnis dan Akuntansi

Homepage: http://journal.stieputrabangsa.ac.id/index.php/jimmba/index

\section{Analisis Pengaruh Customer Trust Terhadap Keputusan Menggunakan Mobile Banking Melalui Perceived Risk dan Perceived Usefulness Sebagai Variabel Intervening (Studi pada Pengguna Aplikasi Mobile Banking Bank BRI di Kantor Cabang Kebumen)}

\author{
Fitria Styarini ${ }^{1}$, Sulis Riptiono ${ }^{2}$ \\ ${ }^{1}$ Sekolah Tinggi Ilmu Ekonomi Putra Bangsa \\ ${ }^{2}$ Sekolah Tnggi Ilmu Ekonomi Putra Bangsa \\ Email: fitriastyarini35@gmail.com
}

\section{ARTICLE INFO}

Article History:

Received: June $10^{\text {th }} 2020$

Accepted: August 19th 2020

Published:August 31st 2020

Keywords:

Customer trust, perceived risk, perceived usefulness,

keputusan menggunakan

\begin{abstract}
Tujuan penelitian ini adalah untuk mengetahui pengaruh customer trust terhadap keputusan menggunakan mobile banking melalui perceived risk dan perceived usefulness sebagai variabel intervening pada pengguna aplikasi mobile banking Bank BRI di Kantor Cabang Kebumen. Populasi pada penelitian ini adalah seluruh nasabah pengguna rekening debet pada Bank BRI Kantor Cabang Kebumen yang menggunakan aplikasi mobile banking BRI. Penelitian ini menggunakan metode purposive sampling dengan sampel sebanyak 100 responden. Berdasarkan metode statistika dilakukan uji validitas, uji reliabilitas, uji asumsi klasik (uji multikolonieritas, uji heteroskedastisitas, dan uji normalitas), uji parsial, uji koefisien determinasi, dan analisis jalur. Hasil penelitian ini menunjukkan bahwa berdasarkan uji validitas dan reliabilitas semua variabel dinyatakan valid dan reliabel. Berdasarkan hasil uji t sub struktur I variabel customer trust berpengaruh positif dan signifikan terhadap perceived risk. Hasil uji $\mathrm{t}$ sub struktur II variabel customer trust berpengaruh positif dan signifikan terhadap perceived usefulness, perceived risk tidak berpengaruh signifikan terhadap perceived usefulness. Kemudian untuk sub struktur III variabel customer trust berpengaruh positif dan signifikan terhadap keputusan menggunakan, perceived risk tidak berpengaruh signifikan terhadap keputusan menggunakan, perceived usefulness berpengaruh positif dan signifikan terhadap keputusan menggunakan.
\end{abstract}

\section{Pendahuluan}

Perbankan merupakan salah satu industri jasa yang ikut andil dalam memanfaatkan perkembangan teknologi yang ada. Bank sebagai lembaga jasa keuangan memiliki tugas untuk menghimpun dana dari masyarakat dalam bentuk deposito dan menyalurkannya kembali kepada masyarakat dalam bentuk kredit atau pinjaman, serta memberikan pelayanan jasa lainnya (Sumarto, 2007). Teknologi informasi yang ada saat ini mampu menunjang 
keberhasilan operasional sebuah bank. Melalui sebuah sistem yang mudah diakses, seorang nasabah dapat melakukan berbagai kegiatan transaksi seperti layanan informasi pengecekan saldo, melakukan transfer dan pembayaran (listrik, air, dan internet), pembelian pulsa dan sebagainya. Kegiatan tersebut dapat dilakukan berkat kemajuan sistem informasi di dunia perbankan, yaitu dengan lahirnya electronic banking (e-banking).

Layanan e-lectronic banking dibagi menjadi enam kategori, yaitu automated teller machine (ATM), phone banking, internet banking, SMS banking, mobile banking, dan international electronic fund transfer (Kristianti dan Pambudi, 2017). Dalam rangka memenuhi tuntutan para nasabah yang menginginkan layanan yang cepat, aman, nyaman dan murah, serta dapat dilakukan dimana saja dan kapan saja. Kini bank menyediakan layanan berbasis teknologi (IT) untuk mempermudah para nasabah dalam melakukan transaksi keuangan melalui layanan mobile banking.

Mobile banking merupakan layanan dalam bentuk aplikasi yang ditawarkan oleh bank yang memungkinkan nasabah melakukan transaksi melalui ponsel dan smartphone. Meski sekilas tampak sama dengan SMS banking, namun mobile banking memiliki fitur yang lebih lengkap pada aplikasi mobile dan dapat diakses melalui jaringan internet maupun SMS. Mobile banking juga berbeda dengan internet banking, hal ini dapat dilihat dari kemudahan dalam mengaksesnya. Salah satu bank yang menawarkan layanan aplikasi mobile banking yaitu PT Bank Rakyat Indonesia (Persero), dengan ribuan unit kerja yang tersebar di seluruh wilayah Indonesia. Di Kabupaten Kebumen sendiri terdapat beberapa unit kerja Bank BRI, salah satunya yaitu Kantor Cabang Bank BRI yang beralamat di Jalan Pahlawan No. 114, Keposan, Kecamatan Kebumen, Jawa Tengah.

Layanan aplikasi mobile banking kini mulai diminati oleh masyarakat di Kabupaten Kebumen yang merupakan kota kecil dengan aktivitas masyarakat yang cukup tinggi. Hadirnya layanan aplikasi mobile banking di Kabupaten Kebumen sangat membantu untuk menunjang aktivitas masyarakat khususnya pada nasabah Bank BRI Kantor Cabang Kebumen. Mobile banking memiliki kegunaan tersendiri bagi nasabah pengguna rekening debet dan nasabah pengguna rekening kredit. Bagi nasabah pengguna rekening debet, mobile banking dapat digunakan untuk daily activity dan kegiatan transaksi lainnya, seperti tarik tunai, transfer antar bank, pembelian pulsa, dan pembayaran tagihan listrik. Transaksi seperti ini umumnya dilakukan untuk menunjang aktivitas nasabah yang memiliki jadwal kerja padat, memiliki kegiatan bisnis, dan nasabah yang sering berbelanja online. Kemudian bagi nasabah pengguna rekening kredit, mobile banking memiliki kegunaan yang berbeda karena pada dasarnya rekening kredit merupakan rekening penampung angsuran yang umumnya digunakan oleh nasabah yang memiliki hutang atau kredit di bank. Dalam hal ini nasabah dapat membayar angsuran melalui aplikasi mobile banking. Kegunaan dari aplikasi mobile banking akan lebih terasa bagi nasabah Bank BRI yang menggunakan rekening debet, karena kegiatan transaksi yang dilakukan merupakan kergiatan transaksi sehari-hari. Oleh karena itu, kegunaan mobile banking lebih difokuskan pada nasabah Bank BRI yang menggunakan rekening debet.

Berdasarkan informasi yang diperoleh dari media Liputan6.com, tahun 2019 jumlah transkasi per hari Bank BRI terus meningkat sekitar 22,72\% yaitu dari rata-rata 22 juta menjadi 27 juta transaksi per hari. Pada H-17 lebaran rata-rata per hari transaksi mencapai 3,42 juta naik menjadi 31,27\%, dibandingkan transaksi periode Januari-April 2019. Sedangkan transaksi mobile banking BRI mengalami kenaikan sebesar 1,12 juta kali transaksi, naik sebesar 9,4\% dibandingkan rata-rata pada periode Januari-April 2019. Dibandingkan tahun 2018 lalu, 
transaksi mobile banking BRI mengalami kenaikan sebesar 23,4\% dari 964 ribu transaksi ke 1,12 juta transaksi. Hingga akhir tahun 2019, transaksi mobile banking BRI sebesar 370,5 juta transaksi atau tumbuh $16,7 \%$ secara setahunan (yoy).

Pada awal tahun 2019 tepatnya pada bulan febuari, Bank BRI kembali meluncurkan aplikasi mobile banking terbaru yaitu BRImo yang merupakan aplikasi digital marketing. Aplikasi BRImo merupakan pengembangan dari aplikasi BRI Mobile yang telah ada sebelumnya. Aplikasi BRImo ini memiliki sedikit perbedaan dari segi tampilan dan fitur yang ditawarkan. Ternyata aplikasi terbaru ini mampu mencatatkan pertumbuhan yang positif, hingga akhir bulan September 2019 pengguna BRImo mencapai 2,2 juta orang. Hal ini menunjukkan tingginya antusiasme para nasabah Bank BRI dalam menerima layanan baru berbasis teknologi.

Berdasarkan wawancara yang telah dilakukan peneliti kepada nasabah Bank BRI Kantor Cabang Kebumen yang menggunakan rekening debet, bahwa dengan menggunakan aplikasi mobile banking terdapat manfaat dan kegunaan yang akan mereka rasakan. Dimana menggunakan mobile banking menjadi lebih prkatis, efektif, dan sangat mempermudah nasabah untuk melakukan transaksi tanpa harus ke bank atau ATM, khususnya bagi nasabah yang memiliki kegiatan bisnis. Karena transaksi dapat dilakukan dimana saja dan kapan saja. Disamping manfaat dan kegunaan yang dimiliki mobile banking, terdapat pula risiko yang akan dirasakan oleh nasabah ketika menggunakan mobile banking yang meliputi risiko biaya, keamanan, dan fitur-fitur yang terdapat pada aplikasi tersebut.

Koening-Lewis, et al, (2010) menyatakan bahwa tidak ada hubungan langsung antara kepercayaan dan niat untuk menggunakan mobile banking, melainkan secara tidak langsung melalui variabel yang sesuai dan risiko yang dirasakan memberikan pengaruh pada niat penggunaan. Selain itu, salah satu alasan orang memilih untuk tidak mengadopsi mobile banking adalah masalah privasi dan kerahasiaan dari saluran elektronik baru yang ditawarkan oleh bank, keterlambatan informasi dan terjadinya eror sistem juga mungkin akan terjadi (Mazhar, et al, 2014). Maraknya kasus kejahatan melalui media elektronik juga menjadi perhatian tersendiri bagi para nasabah sebelum memutuskan menggunakan aplikasi tersebut. Oleh karena itu perlu adanya kepercayaan dari para nasabah sebagai pondasi dasar dalam membangun kepercayaan nasabah terhadap penggunaan aplikasi mobile banking, karena kepercayaan nasabah dapat digambarkan sebagai fungsi tingkat risiko yang terlibat dalam sebuah situasi. Selain itu, kepercayaan nasabah juga dapat memberikan penilaian tentang persepsi manfaat suatu produk.

Setiap nasabah tentu memiliki penilaian tersendiri terhadap kegunaan dan risiko yang akan mereka rasakan jika menggunakan aplikasi mobile banking BRI, karena semua ini tergantung dari seberapa banyak informasi yang dimiliki, pengalaman, situasi, dan kondisi yang nasabah alami. Selain itu juga tergatung dari kemampuan nasabah dalam meminimalisir risiko yang akan diterima. Banyak dari nasabah yang merasa bahwa aplikasi mobile banking memiliki manfaat dan kegunaan yang sangat tinggi, sehingga risiko yang dirasakan menjadi lebih rendah. Ada pula yang berpendapat bahwa risikonya tinggi namun akan sangat berguna ketika dalam keadaan mendesak, sehingga hal ini mampu mendorong nasabah untuk menggunakan aplikasi mobile bangking untuk kegiatan transaksi keuangan.

Oleh karena itu, penelitian ini perlu dilakukan untuk menganalisis seberapa besar kepercayaan yang dimiliki oleh nasabah Bank BRI, dan apakah kepercayaan mempengaruhi 
persepsi risiko dan persepsi kegunaan dari nasabah sehingga mampu mendorong nasabah untuk memutuskan menggunakan aplikasi mobile banking Bank BRI yang nantinya hasil penelitian ini diharapkan dapat membantu dalam meningkatkan kepercayaan, persepsi manfaat, dan meminimalisir risiko yang dirasakan oleh nasabah sesuai dengan hasil penelitian agar nasabah senantiasa menggunakan aplikasi mobile banking BRI untuk kegiatan transaksi keuangan.

\section{Kajian Teori dan Telaah Literatur}

\section{Keputusan Menggunakan}

Peter dan Olson (1999:162), mendefinisikan pengambilan keputusan sebagai proses pengintegrasian yang melibatkan pengetahuan untuk mengevaluasi dua atau lebih alternatif, dan memilih salah satu diantaranya. Dalam konteks produk jasa kita mengenal dengan keputusan menggunakan, yaitu menggunakan layanan yang diberikan oleh pihak perusahaan akan jasa yang mereka tawarkan. Menurut Fatuh dan Widyastuti (2017), keputusan pembelian dapat diasumsikan sebagai keputusan menggunakan. Dalam konteks perusahaan jasa, keputusan pembelian merupakan proses seorang konsumen menggunakan produk berupa layanan yang ditawarkan oleh perusahaan jasa tersebut. Menurut Kotler dan Keller (2009:240), keputusan pembelian adalah keputusan yang diambil berdasarkan preferensi merek-merek yang ada di dalam sebuah pilihan. Adapun indikator yang digunakan dalam pengambilan keputusan menurut Prastiwi (2018), yaitu sebagai berikut: a) mengenali kebutuhan, berlanjut pada prioritas menggunakan pada produk tertentu, b) mencari informasi, c) mengevaluasi alternatif lain, d) keputusan menggunakan, e) evaluasi pasca pengambilan keputusan.

\section{Perceived Usefulness}

Persepsi mengenai kegunaan atau manfaat suatu produk menjadi pertimbangan tersendiri bagi seseorang dalam melakukan pembelian. Konsumen sering kali berfikir mengenai manfaat yang akan ia rasakan jika mengonsumsi atau membeli suatu produk, bukan mengenai atributnya (Sumarwan, 2004:123). Menurut Davis (1989), persepsi kegunaan (perceived usefulnes) merupakan sejauh mana seseorang percaya bahwa menggunakan sistem tertentu akan meningkatkan kinerja pekerjaannya. Terdapat beberapa faktor yang mempengaruhi perceived usefulness, yaitu: perceived product information, price perception, convenience, perceived product, dan service quality. Menurut Davis (2000); Wijaya (2006); Warmika (2016), indikator perceived usefulness yaitu sebagai berikut: a) dapat diakses dimana saja dan kapan saja, b) lebih efektif, c) meningkatkan produktivitas, d) bermanfaat, e) lebih cepat, f) membantu kinerja.

\section{Perceived Risk}

Risiko menjadi salah satu faktor penghambat bagi konsumen untuk melakukan proses pengambilan keputusan pembelian. Persepsi risiko merupakan anggapan subyektif dari konsumen mengenai tinggi rendahnya tingkat risiko yang akan mereka terima ketika menggunakan suatu produk. Mahardika dan Soetomo (2019), mendefinisikan perceived risk sebagai ekspektasi subyektif dari konsumen tentang kerugian yang akan mungkin terjadi dalam upaya mencapai hasil yang diinginkan. Menurut Gbongli dan Ackah (2016) terdapat empat kategori perceived risk dalam konteks mobile banking, yaitu sebagai berikut: a) performance risk, b) financial risk, c) time risk, d) privacy risk. 


\section{Customer Trust}

Kepercayaan merupakan aspek paling penting dalam menjalin sebuah hubungan bisnis, karena dengan adanya kepercyaan maka akan terjalin sebuah komitmen diantara keduanya. Ba dan Pavlou (2002) mendefinisikan kepercayaan sebagai penilaian hubungan seseorang dengan orang lain yang akan melakukan transaksi tertentu sesuai dengan harapan dalam lingkungan yang penuh ketidakpastian. Sedangkan menurut McKnight, at al, (2002), kepercayaan merupakan sebuah keyakinan yang dibangun antara pihak-pihak yang belum saling mengenal baik dalam hal interaksi maupun proses transaksi. Menurut Mowen dan Minor (2002:312), kepercayaan konsumen (consumer beliefs) adalah semua pengetahuan yang dimiliki oleh konsumen dan semua kesimpulan yang dibuat oleh konsumen tentang objek, atribut, dan manfaatnya. Terdapat tiga indikator yang membangun kepercayaan konsumen menurut McKnight, et al, (2002), yaitu sebagai berikut: a) Benevolence, b) Integrity, c) competence.

\section{Model empiris}

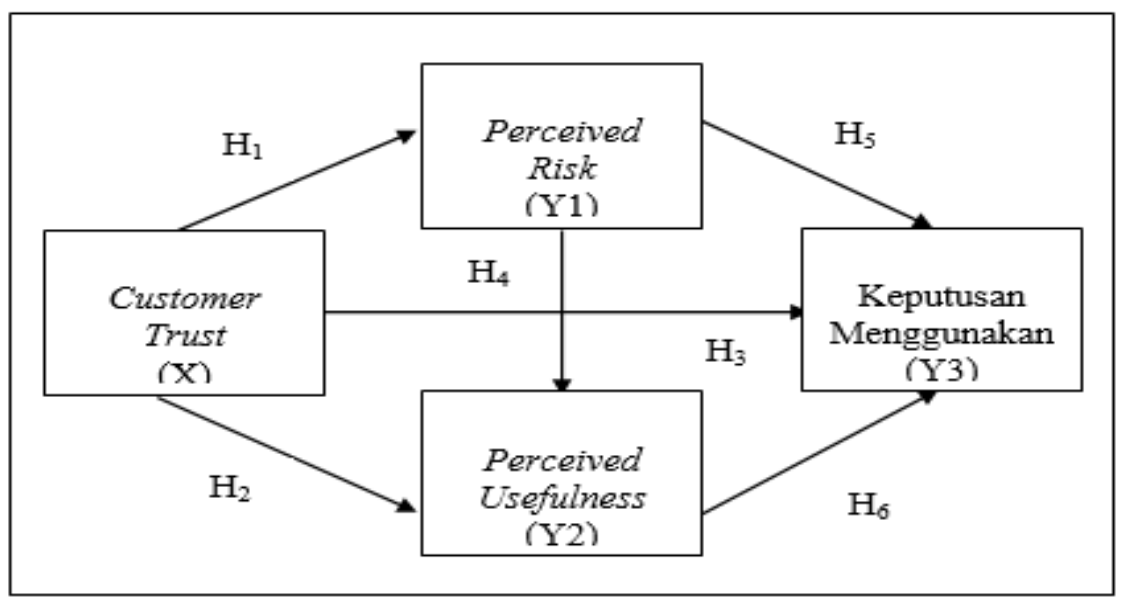

Gambar 1. Model penelitian

\section{Metode Penelitian}

Populasi dalam penelitian ini adalah seluruh nasabah pengguna rekening debet pada Bank BRI Kantor Cabang Kebumen di Jl. Pahlawan No. 114, Keposan Kebumen yang menggunakan Aplikasi mobile banking BRI. Sedangkan jumlah sampel yang digunakan dalam penelitian ini sebanyak 100 responden. Metode pengambilan sampel dengan menggunakan teknik non probability sampling yaitu purposive sampling. Menurut Sugiyono (2006:77), sampling purposive adalah teknik penentuan sampel dengan pertimbangan tertentu. Adapun kriteria atau syarat sampel yang dijadikan responden dalam penelitian ini adalah nasabah pengguna rekening debet pada Bank BRI Kantor Cabang Kebumen yang menggunakan aplikasi mobile banking BRI dengan usia minimal 18 tahun dan saat ini masih aktif menggunakan mobile banking BRI untuk transaksi keuangan. Penelitian ini menggunakan skala likert 5. Teknik analisis data yang digunakan adalah analisis kuantitatif dengan menggunakan program SPSS 23 for windows. 


\section{Hasil dan Pembahasan}

Pengujian validitas dan reliabilitas

Tabel 1. Hasil pengujian validitas dan reliabilitas

\begin{tabular}{|c|c|c|c|c|c|c|}
\hline Variabel & $\begin{array}{c}\text { Item } \\
\text { Pertanyaan }\end{array}$ & $\begin{array}{c}r \\
\text { hitung }\end{array}$ & $\begin{array}{c}\mathrm{r} \text { tabel } \\
(\mathrm{df}= \\
\mathrm{n}-\mathrm{k})\end{array}$ & $\begin{array}{l}\text { Cronbach } \\
\text { Alpha (a) }\end{array}$ & $\begin{array}{c}\mathrm{r} \\
\text { kritis }\end{array}$ & Signifikansi \\
\hline \multirow{3}{*}{$\begin{array}{c}\text { Customer Trust } \\
(\mathrm{X})\end{array}$} & CT 1 & 0,722 & 0,197 & \multirow[t]{3}{*}{0,605} & \multirow[t]{3}{*}{0,60} & \multirow[t]{3}{*}{0,000} \\
\hline & CT 2 & 0,756 & 0,197 & & & \\
\hline & CT 3 & 0,768 & 0,197 & & & \\
\hline \multirow{4}{*}{$\begin{array}{l}\text { Perceived Risk } \\
\text { (Y1) }\end{array}$} & PR 1 & 0,603 & 0,197 & \multirow[t]{4}{*}{0,644} & \multirow[t]{4}{*}{0,60} & \multirow{4}{*}{0,000} \\
\hline & PR 2 & 0,713 & 0,197 & & & \\
\hline & PR 3 & 0,772 & 0,197 & & & \\
\hline & PR 4 & 0,693 & 0,197 & & & \\
\hline \multirow{6}{*}{$\begin{array}{c}\text { Perceived } \\
\text { Usefulness (Y2) }\end{array}$} & PU 1 & 0,721 & 0,197 & \multirow[t]{6}{*}{0,771} & \multirow[t]{6}{*}{0,60} & \multirow[t]{6}{*}{0,000} \\
\hline & PU 2 & 0,710 & 0,197 & & & \\
\hline & PU 3 & 0,648 & 0,197 & & & \\
\hline & PU 4 & 0,704 & 0,197 & & & \\
\hline & PU 5 & 0,718 & 0,197 & & & \\
\hline & PU 6 & 0,591 & 0,197 & & & \\
\hline \multirow{5}{*}{$\begin{array}{l}\text { Keputusan } \\
\text { Menggunakan } \\
\text { (Y3) }\end{array}$} & KM 1 & 0,566 & 0,197 & \multirow{5}{*}{0,695} & \multirow{5}{*}{0,60} & \multirow{5}{*}{0,000} \\
\hline & KM 2 & 0,682 & 0,197 & & & \\
\hline & KM 3 & 0,633 & 0,197 & & & \\
\hline & KM 4 & 0,774 & 0,197 & & & \\
\hline & KM 5 & 0,720 & 0,197 & & & \\
\hline
\end{tabular}

Sumber: Data primer yang sudah diolah (2020).

Berdasarkan tabel 1 semua variabel mempunyai $r$ hitung lebih besar dari $r$ tabel, sehingga semua butir pertanyaan kuesioner dalam penelitian ini dinyatakan valid, yang artinya butirbutir pertanyaan dapat digunakan untuk mengukur apa yang seharusnya diukur. Tabel di atas juga menunjukkan bahwa variabel independen maupun variabel dependen memiliki nilai Cronbach Alpha lebih besar dari r kritis yaitu 0,60 segingga dapat disimpulkan bahwa semua instrumen dalam penelitian ini dinyatakan reliabel.

\section{Uji hipotesis}

Uji parsial (uji t)

Tabel 2. hasil uji t substruktural 1, 2, dan 3

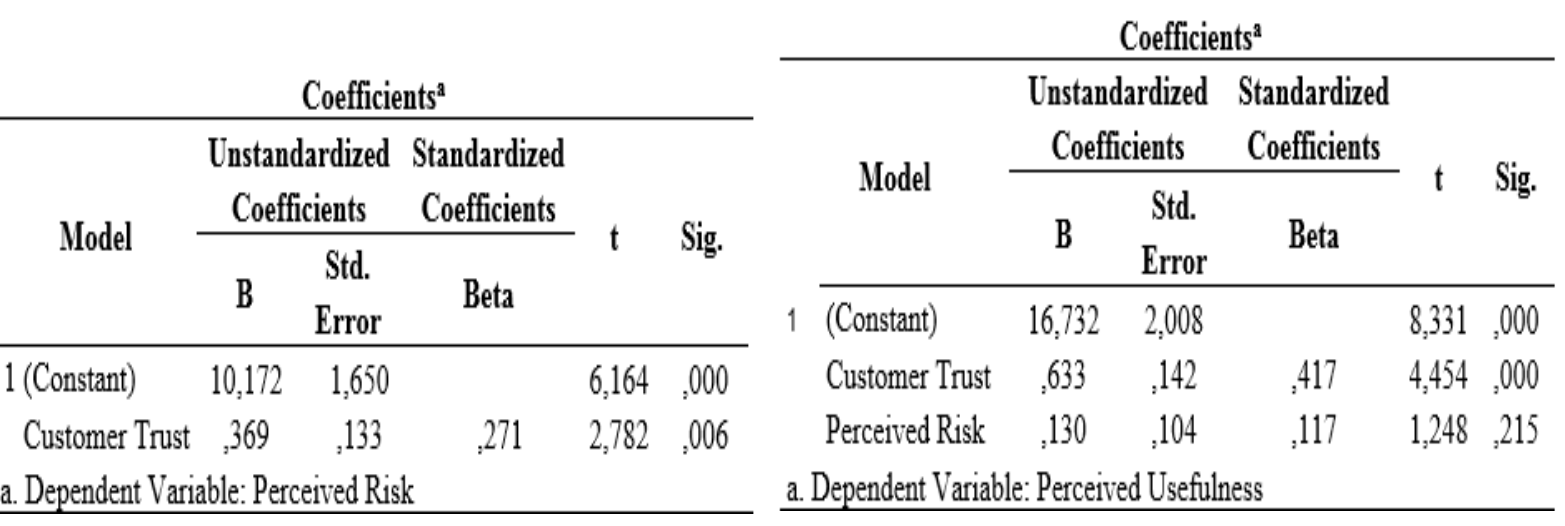




\begin{tabular}{|c|c|c|c|c|c|}
\hline \multicolumn{6}{|c|}{ Coefficients $^{\mathrm{a}}$} \\
\hline \multirow{2}{*}{ Model } & \multicolumn{2}{|c|}{$\begin{array}{c}\text { Unstandardized } \\
\text { Coefficients }\end{array}$} & \multirow{2}{*}{$\begin{array}{c}\text { Standardized } \\
\text { Coefficients } \\
\text { Beta }\end{array}$} & \multirow{2}{*}{$t$} & \multirow{2}{*}{ Sig. } \\
\hline & B & $\begin{array}{l}\text { Std. } \\
\text { Error }\end{array}$ & & & \\
\hline \multirow{4}{*}{$\begin{array}{l}\text { (Constant) } \\
\text { Customer Trust } \\
\text { Perceived Risk } \\
\text { Perceived } \\
\text { Usefulness }\end{array}$} & 4,156 & 1,707 & & 2,435 & 017 \\
\hline &, 507 & 101 &, 400 & 5,001 &, 000 \\
\hline & .055 & 068 & 060 & 811 & .419 \\
\hline &, 358 & 066 & ,430 & 5,438 &, 000 \\
\hline \multicolumn{6}{|c|}{ a. Dependent Variable: Keputusan Menggunakan } \\
\hline
\end{tabular}

Sumber: Data primer diolah, 2020.

\section{Pembahasan}

Variabel customer trust berpengaruh secara signifikan terhadap perceived risk pada nasabah pengguna aplikasi mobile banking Bank BRI di Kantor Cabang Kebumen. Hasil kuesioner menunjukkan bahwa sebagian besar responden memiliki penilaian yang tinggi terhadap variabel customer trust. Hasil positif berkaitan dengan pertanyaan dalam kuesioner yang menyatakan adanya low risk atau persepsi risiko yang rendah pada aplikasi mobile banking, sehingga ketika konsumen merasa risikonya rendah maka hasil yang diperoleh akan positif. Risiko yang dirasakan nasabah pengguna aplikasi mobile banking BRI di Kantor Cabang Kebumen, yaitu biaya yang digunakan untuk setiap transaksi dapat diminimalisir, menghemat waktu, dan fitur yang aman digunakan.

Variabel customer trust berpengaruh secara signifikan terhadap perceived usefulness pada nasabah pengguna aplikasi mobile banking Bank BRI Kantor Cabang Kebumen, hal ini berarti kegunaan atau manfaatnya dirasa semakin tinggi karena adanya kepercayaan yang dimiliki oleh nasabah. Kepercayaan nasabah terhadap layanan aplikasi mobile banking BRI dapat memberikan penilaian bahwa menggunakan mobile banking BRI dapat memenuhi kebutuhan nasabah dalam melakukan transaksi keuangan. Manfaat yang dirasakan nasabah penguna aplikasi mobile banking Bank BRI di Kantor Cabang Kebumen, yaitu melakukan kegiatan transaksi jadi lebih fleksibel dapat dilakukan dimana saja dan kapan saja, menghemat waktu, tidak perlu datang ke ATM atau bank sehingga lebih cepat dalam memenuhi kebutuhan pengguna.

Variabel customer trust berpengaruh secara signifikan terhadap keputusan menggunakan pada nasabah pengguna aplikasi mobile banking BRI Kantor Cabang Kebumen, hal ini berarti pengambilan keputusan untuk menggunakan aplikasi mobile banking semakin tinggi karena adanya kepercayaan yang dimiliki nasabah yang mampu mendorong dalam proses pengambilan keputusan. Kepercayaan yang dimiliki oleh nasabah berawal dari kepercayaan yang mereke miliki terhadap pihak bank dan kepercayaan yang dimiliki dapat meningkatkan kepercayaan terhadap layanan yang ditawarkan oleh pihak bank.

Variabel perceived risk tidak berpengaruh secara signifikan terhadap perceived usefulness, hal ini berarti persepsi risiko yang dirasakan tidak mampu menggambarkan adanya persepsi manfaat atau kegunaan yang tinggi terhadap aplikasi mobile banking, karena persepsi itu sendiri berhubungan dengan situasi. Jadi ketika nasabah membutuhkan mobile banking untuk 
transaksi dalam keadaan mendesak, maka nasabah akan menganggap layanan tersebut memiliki kegunaan yang tinggi, sehingga persepsi risiko yang ada tidak mempu menggambarkan adanya peningkatan persepsi kegunaan dari aplikasi mobile banking BRI.

Variabel perceived risk tidak berpengaruh secara signifikan terhadap keputusan menggunakan aplikasi mobile banking BRI. Dalam penelitian ini terdapat beberapa responden yang memberikan penilain yang rendah tehadap variabel perceived risk aplikasi mobile banking BRI. Hal ini berarti risiko yang dirasakan bukanlah faktor utama yang mendorong keputusan menggunakan, dengan kata lain perceived risk bukanlah faktor yang dapat meningkatkan keputusan menggunakan aplikasi mobile banking dalam kehidupan sehari-hari secara terusmenerus. Berdasarkan hasil penelitian ini terdapat variabel lain yang lebih dominan dalam mempengaruhi keputusan menggunakan aplikasi mobile banking BRI.

Variabel perceived usefulness berpengaruh secara signifikan terhadap keputusan menggunakan aplikasi mobile banking BRI, hal ini berarti keputusan untuk menggunakan aplikasi mobile banking semakin tinggi karena adanya persepsi mengenai manfaat dan kegunaan yang dirasakan oleh nasabah pengguna aplikasi mobile banking Bank BRI di Kantor Cabang Kebumen. Semakin tinggi persepsi kegunaan yang dirasakan maka akan semakin besar pula kemungkinan untuk memutuskan menggunakannya. Transaksi menggunakan aplikasi mobile banking lebih cepat sehingga kebutuhan transaksi yang mendesak dapat segera teratasi dengan cepat tanpa harus ke ATM atau bank. Persepsi kegunaan yang tinggi cenderung akan mendukung perubahan yang terjadi dalam pengambilan keputusan, sehingga dapat dikatan bahwa perceived usefulness merupakan salah satu faktor utama dalam adopsi mobile banking BRI.

\section{Penutup dan Saran}

Customer trust merupakan aspek penting dalam membangun sebuah bisnis, karena dengan adanya kepercayaan maka terjalin sebuah komitmen diantara keduanya. Bagi perusahaan jasa, kepercayaan merupakan pondasi dasar untuk membangun hubungan yang baik dengan pelanggan. Oleh karena itu PT Bank Rakyat Indonesia Persero perlu untuk meningkatkan kepercayaan nasabah agar tumbuh sikap positif terhadap penggunaan layanan mobile banking BRI dengan terus konsisten dalam memenuhi kebutuhan nasabah melalui layanan yang ditawarkan.

Perceived risk merupakan salah satu faktor yang menghambat seseorang untuk melakukan pembelian atau suatu menggunakan produk, karena setiap orang cenderung menghindari adanya risiko. Saat ini sering terjadi kasus penipuan dan pembobolan rekening nasabah melalui layanan elektronik banking, sehingga muncul kekhawatiran tersendiri bagi nasabah. Selain itu, nasabah sering mengeluhkan adanya gangguan sistem transaksi melalui mobile banking sehingga terjadi keterlambatan informasi. Oleh karena itu, penting bagi PT Bank Rakyat Indonesia meminimalisir adanya risiko yang akan dirasakan oleh konsumen mengenai layanan aplikasi mobile banking dengan terobosan untuk memperbaiki keamanan sistem mobile banking.

Perceived usefulness merupakan suatu kepercayaan tentang proses pengambilan keputusan. Menggunakan aplikasi mobile banking membuat kegiatan perbankan menjadi lebih mudah. Oleh karena itu, diharapkan PT Bank Rakyat Indonesia dapat mempertahankan dan 
meningkatkan faktor-faktor yang dapat meningkatkan keputusan menggunakan mobile banking, salah satunya dengan menciptakan aplikasi mobile banking yang dapat digunakan untuk semua tipe smartphone sehingga dapat diakses oleh semua kalangan, karena tidak semua nasabah dapat membeli atau menggunakan yang spesifikasinya tinggi.

Keputusan menggunakan dalam penelitian ini PT Bank Rakyat Indonesia perlu mempertahankan kepercayaan nasabah agar selalu tercipta hubungan yang baik yang secara tidak langsung akan berdampak pada kepercayaan nasabah untuk selalu menggunakan layanan yang ditawarkan oleh bank, selain itu terbentuknya persepsi yang tepat pada nasabah akan menumbuhkan kesan yang baik dan memberikan penilaian yang tepat sehingga persepsi yang dimiliki nasabah terhadap layanan mobile banking akan membuat nasabah tertarik untuk menggunakannya. Karena pada dasarnya nasabah akan menggunakan suatu layanan jika layanan yang ditawarkan dirasa memiliki manfaat atau kegunaan yang tinggi. Oleh karena itu dalam hal ini perlu adanya penyampain informasi yang jelas dan lebih rinci dari pihak bank mengenai produk yang ditawarkan agar nasabah dapat mempersepsikan sebuah layanan dengan baik sehingga tercipta pengambilan keputusan.

\section{Referensi}

Azmi, A. A. C., Yusniza K. dan Nor Haida A. H. 2012. "Perceived risk and the adoption of tax e-filing". World Applied Sciences Journal, 20(4), 532-539.

Ba, S., dan Paul A. Pavlou. 2002. "Evidence of the effect of trust building technology in electronic markets: Price premiums and buyer behavior". MIS quarterly Vol. 26, No. 3, 2002: 243-268.

Cho, Y. C., \& Sagynov, E. (2015). "Exploring factors that affect usefulness, ease of use, trust, and purchase intention in the online environment". International Journal of Management \& Information Systems (IJMIS), 19(1), 21-36.

Davis, F. D. 1989. "Perceived usefulness, perceived ease of use, and user acceptance of information technology". MIS quarterly, 319-340.

Dewi, N. M. A. P., dan I Gde K. Warmika. 2016. “Peran Persepsi Kemudahan Penggunaan, Persepsi Manfaat dan Persepsi Resiko terhadap Niat Menggunakan Mobile Commerce di Kota Denpasar". E-Jurnal Manajemen Vol. 5, No. 4, 2016: 2606-2636.

Fatuh, Miyatul. 2017. "Pengaruh Promosi Penjualan, Perceived Ease of Use, dan Perceived Usefulness terhadap Keputusan Menggunakan Transportasi Online (Studi pada Pengguna Uber di Surabaya Pusat). Jurnal Ilmu Manajemen Vol. 5, No. 4.

Ghozali, Imam. 2006. Aplikasi Analisis Multivariate dengan Program SPSS. Semarang: Universitas Diponegoro.

Gbongli, K., dan Owusu Ackah. 2016. “Selection and Ranking of Perceived Risk Associated with Mobile Banking in West Africa : An AHP Approach from Customer's Perspective". International Journal of Scientific and Enginering Research, 7 (1), 80-86.

Jannah, N. Z. 2017. "Pengaruh Percaived Ease Of Use dan Percaived Usefulness Terhadap Buying Interest dan Buying DecisionMelalui Aplikasi Go-Jek di Kota Samarinda". Jurnal Universitas Mulawarman Vol. 5, No. 4, 2017: 1014-1028. 
Kesharwani, A., dan Shailendra S. B. 2012. "The impact of trust and perceived risk on internet banking adoption in India: An extension of technology acceptance model". International Journal of Bank Marketing, 30(4), 303-322.

Kotler, Philip dan Kevin Lane Keller. 2009. Manajemen Pemasaran Edisi 12. Klaten: PT. Macanan Jaya Cemerlang.

Kristianti, M. L., dan Rilo Pambudi. 2017. “Analisis Pengaruh Persepsi Kemudahan, Persepsi Kemanfaatan, Persepsi Tingkat Kemananan, Dan Fitur Layanan Terhadap Penggunaan Mobile Banking Pada Mahasiswa Di DKI Jakarta. Jurnal Akuntansi Vol. 11, No. 1, Oktober: 50-67.

Kurniawan, D., Hantane S. dan Edwin J. 2013. “Analisis Penerimaan Nasabah terhadap Layanan Mobile Banking dengan Menggunakan Pendekatan Technology Acceptance Model dan Theory of Reasoned Action". Jurnal Strategi Pemasaran Vol. 1, No. 1, 2013: $1-13$.

Mahardika, R. M. dan Harsini S. 2019. “Anteseden Mobile Banking Adoption”. Media Riset Bisnis dan Manajemen Vol. 19, No. 1, April 2019: 45-57.

McKnight, D. Harrison, Vivek Choudhury, dan Charles K. 2002. “Developing and Validating Trust Measures for E-Commerce: An Intgrative Typology". Information System Research Vol 13, No. 3.

Mehrad, D., dan Shahriar M. 2017. “Word of Mouth impact on the adoption of mobile banking in Iran". Telematics and Informatics, 34(7), 1351-1363.

Mowen, John C. Dan Minor, Michael. (2002). Perilaku Konsumen Jiilid 1. Jakarta: Erlangga.

Peter, J. Paul, dan Jerry C. Olson. 1999. “Consumer Behavior, Perilaku Konsumen dan Strategi Pemasaran". Edisi 4. Jakarta: Erlangga.

Prastiwi, I. E. 2018. “Pengaruh Persepsi Anggota Pada Sharia Compliance, Komitmen Agama dan Atribut Produk Islam Terhadap Customer's Trust Yang Berdampak Pada Keputusan Menggunakan Jasa Lembaga Keuangan Syariah (Studi Pada BMT Amanah Ummah Sukoharjo)". Jurnal Ilmiah Ekonomi Islam Vol. 4, No. 1, 2018: 2840 .

Sarwono, Jonathan. 2007. Analisis Jalur unttuk Riset Bisnis dengan SPSS. Yogyakarta: Andi.

Schiffman, L., dan Leslie Lazar K. 2008. Perilaku Konsumen Edisi Ketujuh. Yogyakarta: PT INDEKS.

Sugiyono. 2009. Metode Penelitian Bisnis. Bandung: Alfabeta.

Sugiyono. 2006. Metode Penelitian Bisnis. Bandung: Alfabeta.

Sugiyono. 2010. Metode Penelitian Kuantitatif Kualitatif dan RED. Bandung : Alfabeta.

Suhir, M., Imam Suyadi, dan Riyadi .(2014). “Pengaruh Persepsi Risiko, Kemudahan Dan Manfaat Terhadap Keputusan Pembelian Secara Online (Survei Terhadap Pengguna Situs Website Www. kaskus. co. id)". Jurnal Administrasi Bisnis Vol. 8, No. 1. 
Sumarto, S. (2012). "Membangun Customer Loyalty Nasabah Bank Melalui Customer Satisfaction". Jurnal Riset Ekonomi dan Bisnis Vol. 7, No. 2, 2012: 15-30.

Sumarwan, Ujang. 2004. Perilaku Konsumen: Teori dan Penerapannya dalam Pemasaran. Bogor: Ghalia Indonesia.

Taroreh, O., Rotinsulu J. J. dan Rudy W. 2015. “Pengaruh Persepsi Konsumen dan Kepercayaan terhadap Penggunaan Jasa Asuransi pada Asuransi Jasindo Manado". Jurnal Riset Ekonomi, Manajemen, Bisnis dan Akuntansi Vol. 3, No. 3, September 2015: 312-321.

Tjiptono, Fandy. 2008. Strategi Pemasaran Edisi III. Yogyakarta: CV. ANDI OFFSET.

Wahyuningtyas, Y.F., dan Widiastuti D. 2015. "Analisis Pengaruh Persepsi Risiko, kemudahan, dan Manfaat terhadap Keputusan Pembelian Secara Online (Studi Kasus pada Konsumen Barang Fashion di Facebook). Jurnal Kajian Bisnis Vol. 23, No. 2. 